\title{
Aplikasi Pelayanan Masyarakat Menggunakan GIS LSM Dan Ormas Memanfaatkan Metode Djikstra Dikantor Kesbangpol Pekanbaru
}

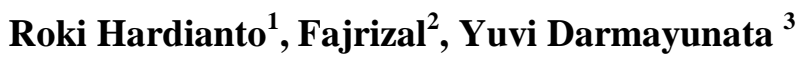 \\ ${ }^{1,2,3}$ Prodi Teknik Informatika Fakultas Ilmu Komputer Universitas Lancang Kuning \\ Jl. Yos Sudarso KM. 08 Kec.Rumbai, Pekanbaru, Riau, telp. 08117532015 \\ e-mail: ${ }^{1}$ roki@ unilak.ac.id, ${ }^{2}$ fajrizal@unilak.ac.id, ${ }^{3}$ yuvidarmayunata@unilak.ac.id
}

\begin{abstract}
Abstrak
Sistem Informasi Geografis adalah sebuah system informasi berbasis website yang terintegrasi dengan pemetaan menggunakan mapping, sehingga mudah dalam pengambilan keputusan. Sistem Informasi Geografis pada penelitian ini digunakan dalam memetakan sebaran Organisasi Masyarakat dan Lembaga Swadaya Masyarakat terdaftar di Kesbangpol Kota Pekanbaru sehingga dapat membantu masyarakat dalam memperoleh informasi. Dalam memberikan informasi jalur terdekat menuju koordinat tujuan menggunakan algoritma djikstra. Metode djikstra adalah sebuah metode yang membantu dalam memberikan jarak terdekat terhadap titik koordinat. Aplikasi Sistem Informasi Geografis yang dirancang ini dapat membantu pihak Kesbangpol Pekanbaru dan masyarakat untuk memperoleh informasi berupa spasial dan non spasial. Pada proses pengumpulan data, peneliti datang langsung kelokasi mitra untuk memperoleh titik koordinat. Pembuatan Peta Sistem Informasi Geografis menggunakan bahasa pemrograman PHP dan database mysql.
\end{abstract}

Kata kunci: Sistem Informasi Geografis, Kota Pekanbaru, Pemetaan, LSM.

\begin{abstract}
Geographic Information System is a website-based information system that is integrated with mapping using mapping, making it easy to make decisions. The Geographic Information System in this study is used in mapping the distribution of registered Community Organizations and Non-Governmental Organizations in the Kesbangpol Kota Pekanbaru so that it can assist the public in obtaining information. In providing information on the closest path to the destination coordinates using the Dijkstra algorithm. The Dijkstra method is a method that helps in providing the closest distance to the coordinates. The application of this Geographical Information System that design can improve the Kesbangpol Pekanbaru and the community to obtain information in the form of spatial and non-spatial. In the process of collecting data, researchers come directly to partner locations to receive coordinate points. Making a Geographic Information System Map using the PHP programming language and MySQL database.
\end{abstract}

Keywords: Geographic Information System, Pekanbaru City, Mapping, LSM.

\section{Pendahuluan}

Menjadi kota madani adalah impian walikota Pekanbaru yang sejak awal telah digadanggadang. Setiap SKPD dalam lingkungan kota Pekanbaru telah melakukan inovasi berbasis smart city. Termasuk Badan Kesatuan Bangsa dan Politik (Kesbangpol) Pekanbaru dalam proses pelayanannya. Sejak berdiri dan melayani masyarakat masih secara manual, sedangkan kota 
yang telah merujuk smart city harus melakukan revolusi pelayanan secara menyeluruh kepada tersistem. Dalam hal ini Fakultas Ilmu Komputer Universitas Lancang Kuning sangat mendukung langkah pemerintah dalam mewujudkan smart city Pekanbaru. Wujud dukungannya adalah dengan melakukan MOU dengan Kesbangpol Pekanbaru dalam membangun web system dengan 6 sub bagian pelayanan. Salah satunya adalah layanan pemetaan terhadap pelayanan Kesbangpol Pekanbaru kepada masyarakat. Ormas, yayasan, LSM dan organisasi lain akan mengajukan proses perizinan kepada Kesbangpol sebagai bentuk pengakuan oleh pemerintah daerah. Begitu juga di Kesbangpol Pekanbaru melayani hal itu semua, yang menjadi kendala semua arsip pendaftaran masih tercatat secara manual. Hal ini tentu akan menyulitkan dalam proses perpanjangan dan keterbukaan informasi public. Dengan dibangunnya system pemetaan, bisa mendukung kinerja Kesbangpol Pekanbaru.

Sebagian Besar Masyarakat kota Pekanbaru tidak mengetahui adanya organisasi terdaftar maupun organisasi tidak terdaftar. Masalah lain dan menjadi pertimbangan adalah perlunya pengembangan sistem Pemetaan yang mampu menyediakan data dan informasi yang sebelumnya tidak dimiliki oleh Kesbangpol kota Pekanbaru. Sebelumnya untuk mengetahui informasi Organisasi yang terdaftar di Kesbangpol kota Pekanbaru, masyarakat harus datang langsung ke kantor Kesbangpol kota Pekanbaru. Hal ini menyebabkan masalah waktu dan tenaga.

Menurut penelitian [1] primasa dan yogi menjelaskan pemetaan lokasi mitra Coca Cola yang berlangganan dari perusahaan coca cola yang ada di padang. Lokasi dipetakan melalui system informasi geografis menggunakan metode djikstra. Pada penelitian [2] yang mengangkat topik penelitian pembuatan E-Learning untuk SMK Swasta menggunakan Bahasa pemprograman php dan database mysql. Peneliti menjelaskan proses perencanaan membangun sebuah E-Learning hingga penggunaannya oleh siswa dan guru didalam proses belajar mengajar.Pada penelitian [3] menjelaskan lokasi SPBU Pertamina di kota Padang menggunakan system informasi geografis dengan menggunakan metode djikstra dengan bahasa pemprograman php dan database mysql. Sistem ini bisa membantu pengguna untuk mengetahui lokasi SPBU Pertamina terdekat dari lokasi pengguna.[4] dalam penelitian nya menjelaskan pemetaan sarana prasarana departemen agama yang berada di kota Sungai Penuh, Jambi menggunakan web system. Sarana prasarananya berupa masjid, gereja, dan lainnya yang dibangun oleh pemerintah kota Sungai Penuh agar masyarakat mengetahui lokasinya. [5] menjelaskan tentang penentuan calon lokasi perumahan berdasarkan Land Use kota Depok, Jalan Utama, Saluran dan Kemiringan Tanah. Pada penelitian tersebut peneliti menggunakan metode deskriptif dalam menguraikan hasil penelitian

Pada penelitian [6] SIG penentuan lokasi tercepat bagi pemadam kebakaran menggunakan metode djikstra dan metode a-star. Lokasi hidran air sangat mempengaruhi dalam percepatan proses pemadaman.System ini dibangun menggunakan bahasa pemprograman php dan database mysql. Bahasa pemprograman php dan mysql adalah bahasa pemprograman yang lazim digunakan pada setiap proses perancangan web system termasuk web system pemgambilan absensi dan surat cuti kerja pada jurnal [7].Pada proses penggunaan peta dalam web system, peneliti memanfaatkan google api key agar proses manipulasi dan integrasi dalam peta jadi lebih baik. Google api key adalah sebuah metode yang dikeluarkan oleh mesin pencarian google dalam pemprosesan peta dan telah lazim digunakan pada penelitian terdahulu seperti pada penelitian [8].Aplikasi android adalah solusi kepada pengembang web sistem agar lebih mudah dalam penggunaan aplikasi, seperti halnya pada jurnal penelitian [9].[10] Sistem informasi geografis yang dibangun adalah informasi SPBU yang ada di kabupaten Jember dengan sampel 33 SPBU dalam memberikan keputusan dipengaruhi oleh kriteria, cost, dan reverse cost. 
Padapenelitian [1],[3],[6],[8] kemiripan penelitian adalah sama-sama meneliti tentang system informasi geografis menggunakan metode djikstra.Perbedaannya terletak pada objek yang diteliti. Sedangkan pada penelitian [7],[2] hasil penelitian berbeda dengan penelitian saat ini kesamaannya hanya pada penggunaan bahasa pemprograman yang digunakan yaitu bahasa pemprograman php dan database mysql. Pada penelitian [2] tentang rancang bangun e-learning dan [7] pembanguan system pengajuan cuti secara online dengan bahasa pemprograman php dan database mysql.

Sedangkan pada penelitian [4],[5],[10] kemiripan penelitian adalah tentang system informasi geografis, perbedaannya hanya pada penggunaan metode dan objek yang diteliti. Pada penelitian [9] sistem informasi yang dibangun menggunakan interface android sehingga lebih memudahkan user dalam penggunaannya, penelitian ini jelas berbeda dengan penelitian ini karena pada penelitian hanya membangun antar muka berbasis web base.

Meskipun sudah banyak yang melakukan penelitian ini sebelumnya, tapi pada penelitian ini, peneliti membuat inovasi baru dengan membuat sebuah website dari hasil pencarian algoritma djikstra dengan menggunakan bahasa pemprograman php dan database mysql dan didukung dengan API google dalam mengintegrasikan website dari google map ke dalam website yang dibangun. Dengan website tersebut, Kesbangpol Pekanbaru tidak saja memberikan akses kepada pengguna website dalam mentracking koordinat mitra, tetapi juga dapat melakukan tata kelola berupa pencatatan mitra yang terdaftar di Kesbangpol Pekanbaru.

\section{Metode Penelitian}

Dalam pemodelan sistemnya yang dibangun menggunakan pemodelan waterfall. Pemodelan waterfall adalah sebuah pemodelan dalam penelitian, dimana memiliki tahapan penelitian yaitu melakukan perencanaan, pengumpulan data dari observasi, wawancara dan study pustaka, analisis, perancangan dan pemograman serta implementasi. Sedangkan dalam pemprosesan jarak terdekat terhadap koordinat yang dituju menggunakan metode djikstra. Metode djikstra menggunakan beberapa langkah yang digunakan sebagai berikut

a. Menentukan simpul awal dan simpul tujuan.

b. Memberikan label simpul sementara

c. Memberikan nilai bobot jarak antar simpul.

d. Menghapus label sementara dan diperbaharui dengan label simpul permanen

e. Memeriksa simpul berikut yang akan dikunjungi, dan membandingkan bobot nilai baru dengan bobot nilai lama.

f. mengulangi proses dari langkah "kelima" sampai mendapatkan akhir hasil proses jalur terpendek pada node akhir.

g. Memetakan jalur terpendek pada system informasi geografis.

Algoritma djikstra adalah algoritma pencarian jarak terpendek pada proses penemuan jalur terdekat dalam mengambil keputusan. Algoritma Djikstra merunut rute-rute terpendek kepada semua rute yang ada dalam sebuah bagan graf berarah sehingga menemukan optimalisasi jarak terdekat sebagai rule yang rekomendasikan dalam menentukan keputusan.

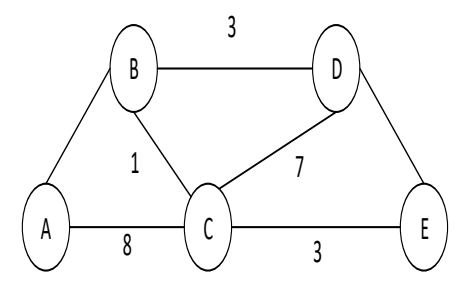

Gambar 1. Bagan Pohon Keputusan 
Gambar diatas merupakan sebuah bagan dalam proses algoritma djikstra yang digambarkan dalam bentuk grab berarah. Algoritma akan memberikan rekomendasi keputusan dengan jarak terpendek sebagai keputusan akhir.

Dari tampilan simpul di graf pada table 1 dapat digambarkan jarak antar simpul adalah sebagai berikut

$$
\begin{aligned}
& A \rightarrow B=4 \\
& A->C=8 \\
& B->C=1 \\
& B->D=3 \\
& C \rightarrow D=7 \\
& C \rightarrow E=3 \\
& D \rightarrow E=8
\end{aligned}
$$

Maka sebagai keputusan akhir dari simpul graf berdasarkan algoritma djikstra adalah sebagai berikut A $\rightarrow$ B $\rightarrow C$ C $>E=4+1+3=8$ sebagai simpul jarak terpendek. Simulasi pencarian jarak terpendek digambarkan pada tabel 1 dibawah ini

Tabel 1. Penyelesaian Pada Sebuah Kasus

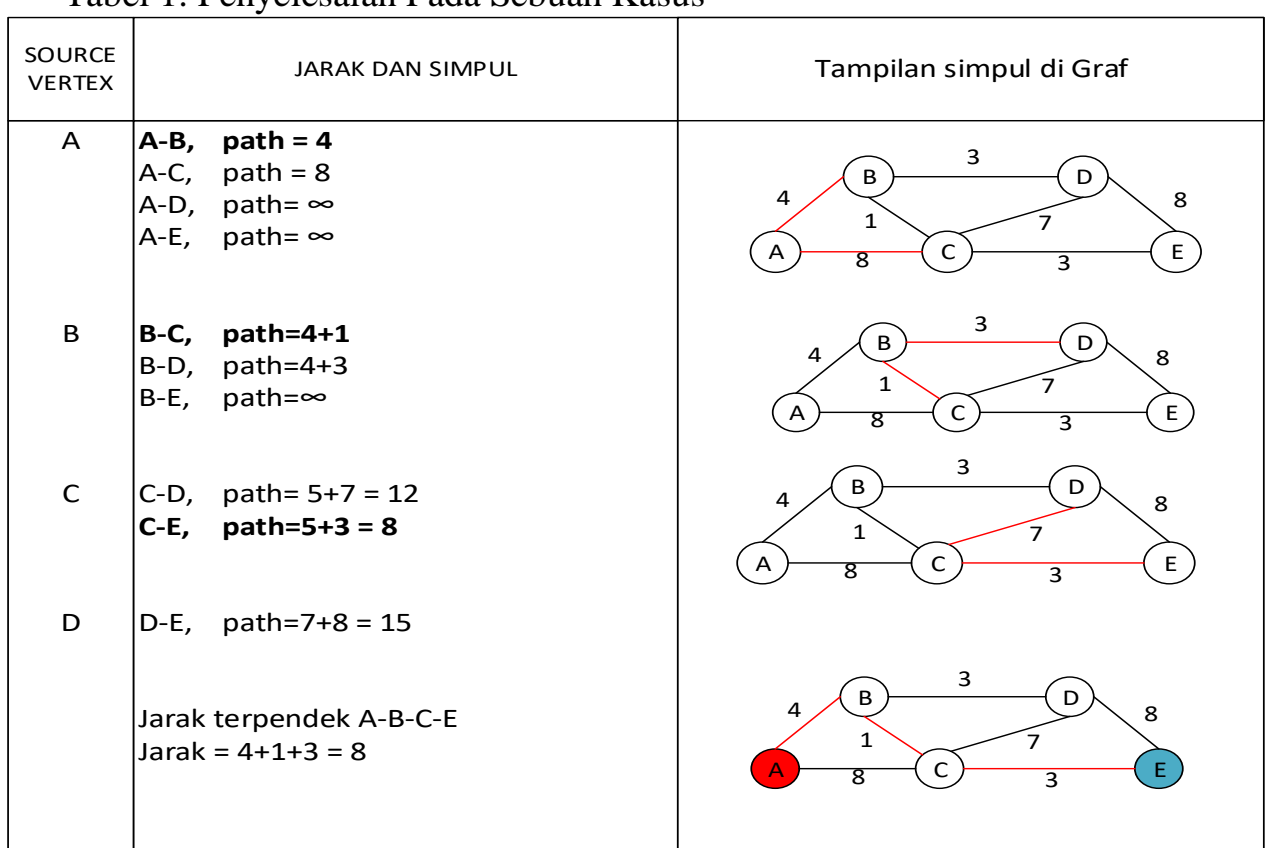

\section{Hasil dan Pembahasan}

Untuk mendapatkan hasil pencarian jalur terpendek pada algoritma djikstra maka perlu dilakukan pengujian system melalui pencarian jalur terpendek dengan rumus sehingga dapat ditentukan selisih hasil dari keputusan yang akan dipetakan. Berikut ini adalah proses perhitungannya :

Dimana:

$\mathrm{Sj}=$ selisih jarak (nilai rata-rata)

$\mathrm{p} 1=$ jarak pengukuran

$$
s_{j}=\left(\frac{\sum_{i-1}^{n}\left(p_{1}-p_{2}\right)}{N}\right) \times 100 \%
$$

p2 = jarak yang dihasilkan djikstra 


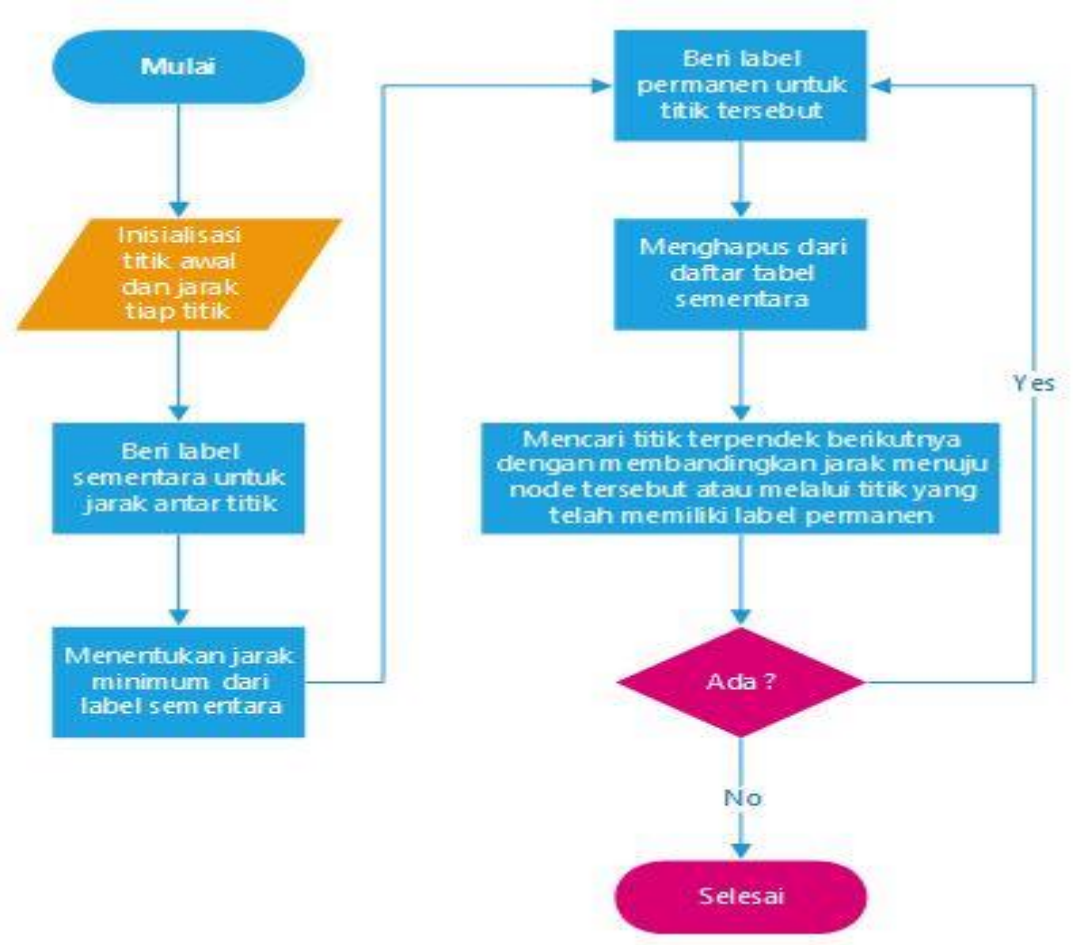

Gambar 2. Flowchart Algoritma Djikstra

Diatasi adalah alur flowchart proses algoritma djikstra dalam menemukan jarak terpendek / terdekat dalam antar node titik yang telah ditentukan. Tahapan pertama dalah proses inialisasi titik node awal dan menetukan jarak setiap node. Kemudian memberi label sementara untuk jarak antar node dan selanjutnya menentukan jarak minimum dari label sementara. Setelah itu memberikan label permanen. Setelah itu jarak minimum antar node dibandingkan untuk mendapatkan jarak terpendek antar node. Proses ini diulang jika masih ada jarak lain yang bisa dihitung. Jika tidak ada lagi maka proses selesai dan jarak terpendek didapat.

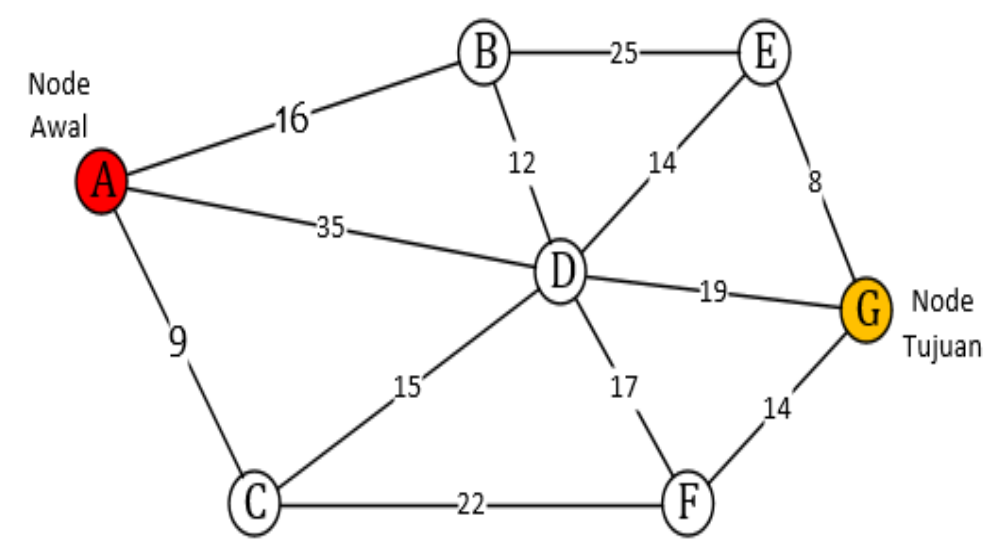

Gambar 3. Node Algoritma Djikstra 
Selanjutnya dilakukan pengujian pada nodenya. Setiap node akan dilakukan pengecekan jarak dengan node terakhir adalah node warna hijau. Rule (jarak) yang didapat adalah :
1. $\mathrm{A}+\mathrm{B}+\mathrm{E}+\mathrm{G}$
2. $\mathrm{A}+\mathrm{B}+\mathrm{D}+\mathrm{E}+\mathrm{G}$
3. $\mathrm{A}+\mathrm{B}+\mathrm{D}+\mathrm{G}$
4. $\mathrm{A}+\mathrm{D}+\mathrm{G}$
5. $\mathrm{A}+\mathrm{D}+\mathrm{B}+\mathrm{E}+\mathrm{G}$
6. $\mathrm{A}+\mathrm{D}+\mathrm{E}+\mathrm{G}$
7. $\mathrm{A}+\mathrm{D}+\mathrm{F}+\mathrm{G}$

8. $\mathrm{A}+\mathrm{C}+\mathrm{F}+\mathrm{G}$

9. $\mathrm{A}+\mathrm{C}+\mathrm{D}+\mathrm{B}+\mathrm{E}+\mathrm{G}$

10. $\mathrm{A}+\mathrm{C}+\mathrm{D}+\mathrm{E}+\mathrm{G}$

11. $\mathrm{A}+\mathrm{C}+\mathrm{D}+\mathrm{G}$

12. $\mathrm{A}+\mathrm{C}+\mathrm{D}+\mathrm{F}+\mathrm{G}$

Tabel 2: Hasil Algoritma Djikstra

\begin{tabular}{|c|c|c|c|c|c|c|c|c|c|c|}
\hline $\begin{array}{l}\mathrm{N} \\
\mathrm{o}\end{array}$ & Unvisite (Q) & Visited (S) & $\begin{array}{c}\text { Curre } \\
\text { nt }\end{array}$ & A & B & $\mathrm{C}$ & $\mathrm{D}$ & $\mathrm{E}$ & $\mathrm{F}$ & G \\
\hline & $\begin{array}{c}\{\mathrm{A}, \mathrm{B}, \mathrm{C}, \mathrm{D}, \mathrm{E}, \\
\mathrm{F}, \mathrm{G}\}\end{array}$ & $\{-\}$ & & $\begin{array}{l}(0, \\
-) 0\end{array}$ & $\begin{array}{l}(\infty, \\
-) 0\end{array}$ & $\begin{array}{l}(\infty, \\
-) 0\end{array}$ & $\begin{array}{l}(\infty, \\
-) 0\end{array}$ & $\begin{array}{c}(\infty,- \\
) 0\end{array}$ & $\begin{array}{l}(\infty,- \\
)\end{array}$ & $\begin{array}{c}(\infty,- \\
) 0\end{array}$ \\
\hline 1 & $\begin{array}{r}\{\mathrm{B}, \mathrm{C}, \mathrm{D}, \mathrm{E}, \mathrm{F}, \\
\mathrm{G}\}\end{array}$ & $\{\mathrm{A}\}$ & A & & $\begin{array}{l}\text { (16, } \\
\text { A) } 1\end{array}$ & $\begin{array}{l}(9, \\
\text { A) } \\
1\end{array}$ & $\begin{array}{l}(35, \\
\text { A) } 1\end{array}$ & $\begin{array}{l}(\infty \\
\text { A) } 1\end{array}$ & $\begin{array}{l}(\infty \\
\text { A) } 1\end{array}$ & $\begin{array}{l}(\infty, \\
\text { A) } 1\end{array}$ \\
\hline 2 & $\begin{array}{r}\{\mathrm{B}, \\
, \mathrm{D}, \mathrm{E}, \mathrm{F}, \mathrm{G}\}\end{array}$ & $\{\mathrm{A}, \mathrm{C}\}$ & $\mathrm{C}$ & & $\begin{array}{l}\text { (16, } \\
\text { A) } 1\end{array}$ & & $\begin{array}{l}(24, \\
\text { C) } 2\end{array}$ & $\begin{array}{l}(\infty, \\
\mathrm{C}) 2\end{array}$ & $\begin{array}{l}(31, \\
\text { C)2 }\end{array}$ & $\begin{array}{l}(\infty, \\
\mathrm{C}) 2\end{array}$ \\
\hline 3 & $\{\mathrm{D}, \mathrm{E}, \mathrm{F}, \mathrm{G}\}$ & $\{\mathrm{A}, \mathrm{B}, \mathrm{C}\}$ & B & & & & $\begin{array}{l}\text { (24, } \\
\text { C) } 2\end{array}$ & $\begin{array}{l}\text { (41, } \\
\text { B)3 }\end{array}$ & $\begin{array}{l}(31, \\
\text { C)2 }\end{array}$ & $\begin{array}{l}(\infty, \\
\text { B) } 3\end{array}$ \\
\hline 4 & $\{\mathrm{E}, \mathrm{F}, \mathrm{G}\}$ & $\{\mathrm{A}, \mathrm{B}, \mathrm{C}, \mathrm{D}\}$ & D & & & & & $\begin{array}{c}(38, \mathrm{D} \\
) 4\end{array}$ & $\begin{array}{l}(31, \\
\text { C) } 2\end{array}$ & $\begin{array}{c}(43, \mathrm{D} \\
) 4\end{array}$ \\
\hline 5 & $\{\mathrm{E}, \mathrm{G}\}$ & $\begin{array}{l}\{\mathrm{A}, \mathrm{B}, \mathrm{C}, \mathrm{D}, \\
, \mathrm{F}\}\end{array}$ & $\mathrm{F}$ & & & & & $\begin{array}{c}(38, \mathrm{D} \\
) 4\end{array}$ & & $\begin{array}{c}(43, \mathrm{D} \\
) 4\end{array}$ \\
\hline 6 & $\{G\}$ & $\begin{array}{l}\{\mathrm{A}, \mathrm{B}, \mathrm{C}, \mathrm{D}, \mathrm{E}, \\
\mathrm{F}\}\end{array}$ & $\mathrm{E}$ & & & & & & & $\begin{array}{c}(43, \mathrm{D} \\
) 4\end{array}$ \\
\hline 7 & $\{-\}$ & $\begin{array}{l}\{\mathrm{A}, \mathrm{B}, \mathrm{C}, \mathrm{D}, \mathrm{E}, \\
\mathrm{F}, \mathrm{G}\}\end{array}$ & G & & & & & & & \\
\hline
\end{tabular}

Dari beberapa rule yang tersedia maka didapat dari penelusuran rule keputusan dari bebrapa rule yang didapat dari gambar 3. Dibawah ini adalah keputusan rule terpendek berdasarkan pencarian algoritma djikstra yaitu $\mathrm{A}+\mathrm{C}+\mathrm{D}+\mathrm{G}=9+15+19=43$ merupakan jarak terpendek dari node $\mathrm{A}$ ke node $\mathrm{G}$ dibandingkan rule lain yang didapat.

Tabel 3: Keputusan Algoritma Djikstra

\begin{tabular}{|c|l|l|c|}
\hline From & To & \multicolumn{1}{|c|}{ Path } & Length / Cost \\
\hline A & B & A - B & 16 \\
\hline A & C & A - C & 9 \\
\hline A & D & A - C - D & 24 \\
\hline A & E & A - C - D - E & 38 \\
\hline A & F & A - C - F & 31 \\
\hline A & G & A - C - D - G & 43 \\
\hline
\end{tabular}




\subsection{Implementasi Sistem}

Pada tahap ini proses pengujian system yang telah dibangun untuk dilakukan ujicoba melihat penerapan dan penggunaan sisyem yang bisa membantu dalam pengolahan data. Pada tahap ini akan dilakukan uji publik terhadap pelayanan system yang dibangun untuk melihat kelemahan dan kelebihan.

\subsubsection{Implementasi Login Admin}

Pada lama login ini adalah laman dimana admin melakukan proses control web GIS. System akan memvalidasi username dan password admin ketika login, apabila username dan password salah maka secara otomatis akan menolak dan proses login gagal. Apabila username dan passwordnya sesuai dengan akun yang didatabase maka akan secara otomatis proses akan di alihkan ke laman utama admin.

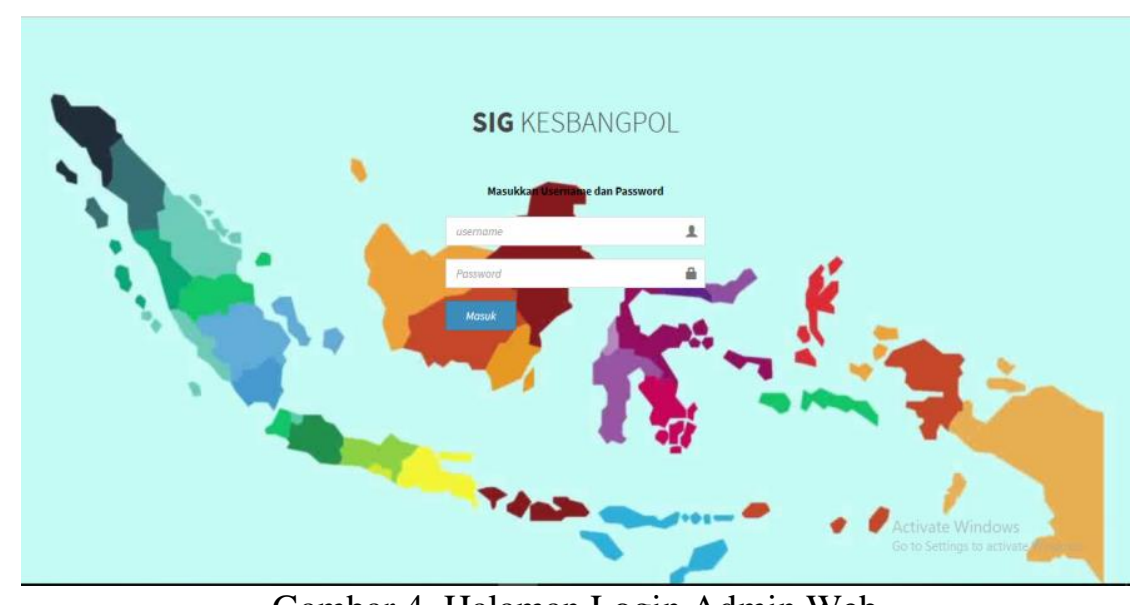

Gambar 4. Halaman Login Admin Web

\subsubsection{Laman Utama Admin}

Laman yang digunakan admin dan operator dalam mengelola website GIS Kesbangpol Pekanbaru.

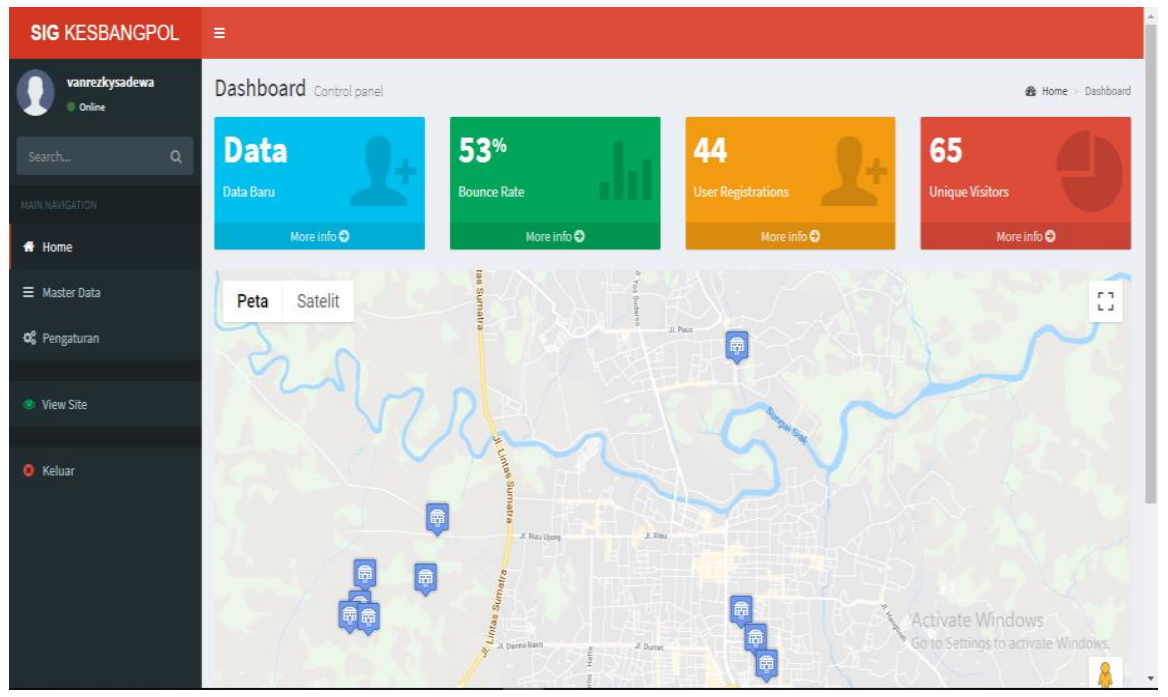

Gambar 5. Halaman Admin 


\subsubsection{Laman Edit Data}

Halaman proses edit data LSM, Yayasan dan Ormas jika terjadi perubahan data atau proses pengajuan izin kembali dengan memperbaharui beberapa atribut pada detail data

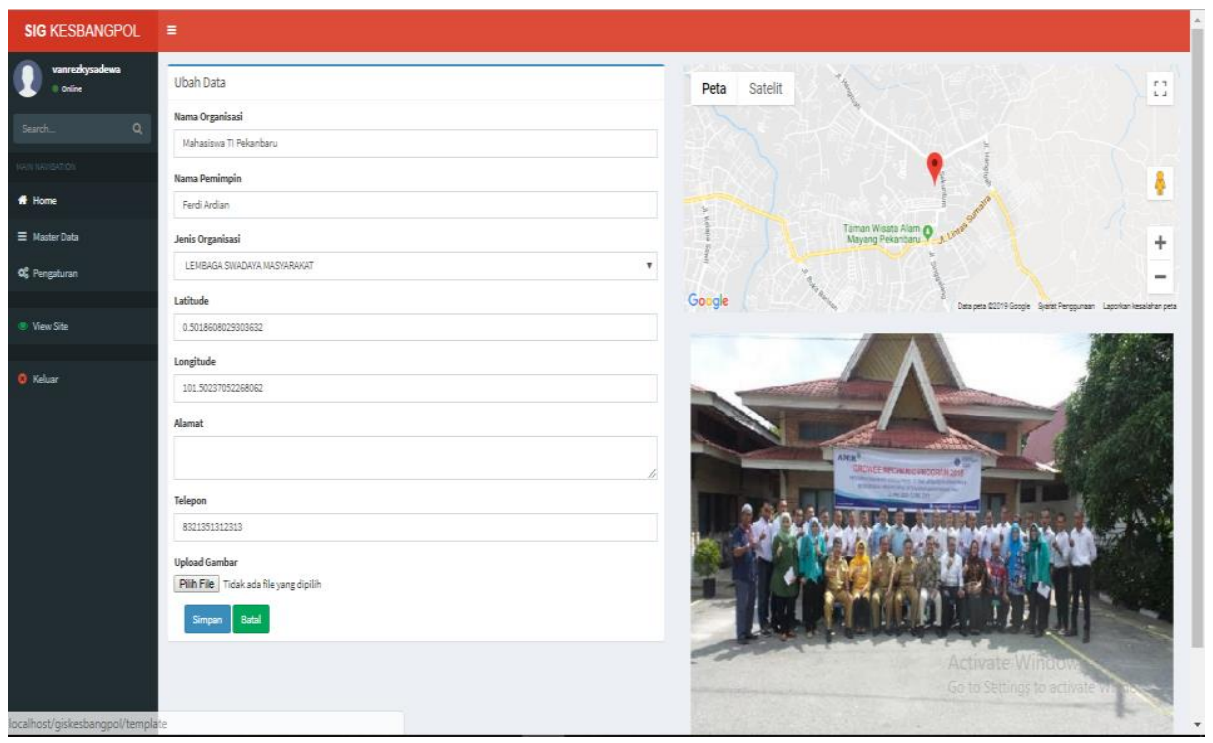

Gambar 6. Halaman Edit Data (Halaman Admin)

\subsubsection{Laman Utama Website}

Halaman beranda website GIS Kesbangpol Pekanbaru. Pada laman ini memberikan informasi terbaru pada Kesbangpol Pekanbaru, susunan organisasi, dan lain sebagainya.
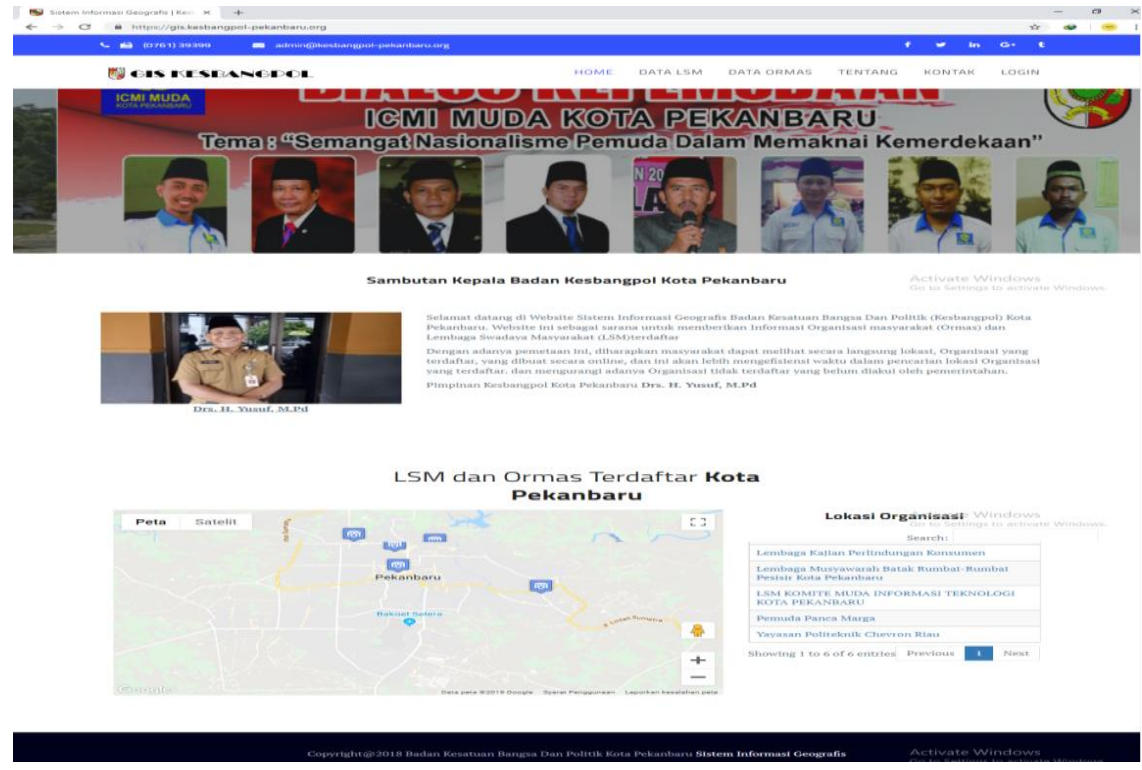

Gambar 7. Halaman Utama Website 


\subsubsection{Implementasi Tracking}

Halaman tracking lokasi LSM, Yayasan atau Ormas dengan lokasi GPS user yang melakukan tracking hingga website/system memberikan lokasi terdekat daripada banyak lokasi yang diberikan oleh system

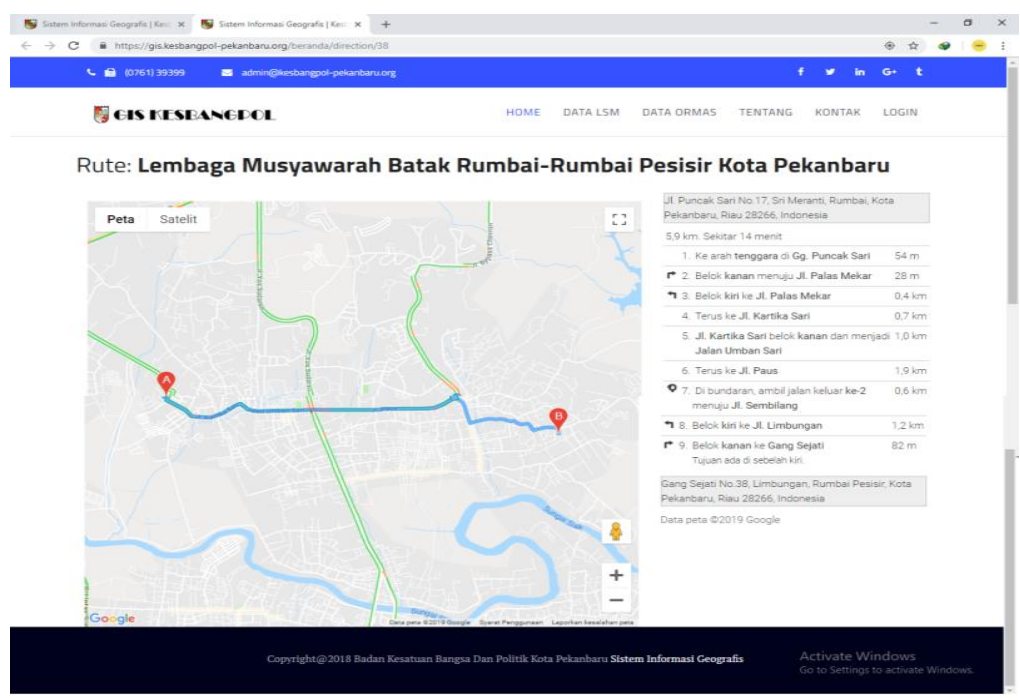

Gambar 8. Halaman Traking Lokasi Mitra

\section{Kesimpulan}

Badan Kesatuan Bangsa dan Politik Kota Pekanbaru sangat menyambut baik inovasi yang telah diberikan Fakultas Ilmu Komputer Universitas Lancang Kuning berupa Sistem Informasi Geografis. Sistem Informasi Geografis sangat membantu dalam memetakan titik koordinat lokasi alamat mitra yang terdaftar di Kesbangpol dan dengan system ini bisa membantu pemerintah kota Pekanbaru dalam percepatan perwujudan smart city dan keterbukaan publik dalam hal pelayanan. Pelayanan Kesbangpol lebih efesien kepada masyarakat baik dari segi waktu dan ekonomis.

Pada penelitian kedepannya diharapkan hasil penelitian ini bisa dikembangkan dalam proses pembangunan aplikasi berbasis android. Karena dengan perkembangan teknologi dan smartphone setiap saat, selain itu sesuai dengan harapan pemerintah indonesia dalan proses peningkatan internet diseluruh indonesia dengan proyek tol langit. Karena pada hasil penelitian ini hanya berupa antar muka desktop.

\section{Daftar Pustaka}

[1] Y. Primadasa, "Pencarian Rute Terpendek Menggunakan Algoritma Dijkstra Pada Sig Berbasis Web Untuk Distribusi Minuman,” J. KomTekInfo Ilmu Komput., vol. 2, no. 2, pp. 47-54, 2015.

[2] H. T. Sihotang, "Pembuatan Aplikasi E-Learning Pada SMK Swasta Pariwisata Imelda Medan," J. Mantik Penusa, vol. 1, no. 2, pp. 70-75, 2017.

[3] B. Junanda, D. Kurniadi, and Y. Huda, "Pencarian Rute Terpendek Menggunakan Algoritma Dijkstra pada Sistem Informasi Geografis Pemetaan Stasius Pengisian Bahan Bakar Umum," J. Vokasional Tek. Elektron. Inform., vol. 4, no. 1, pp. 1-8, 2016.

[4] D. W. T. Putra and Kadris, "Sistem Informasi Geografis Pemetaan Sarana Prasarana Departemen Agama Kota Sungai Penuh Berbasis Web," Teknoif, vol. 4, no. 2, pp. 76$81,2016$. 
[5] R. Apriyanti and F. Rully, "Pemanfaatan Sistem Informasi Geografis (SIG) Dalam Penentuan Lokasi Perumahan Di Kota Depok," Pros. Semin. Ilm. Nas. Komput. dan Sist. Intelijen, vol. 8, no. Kommit, pp. 321-330, 2014.

[6] D. S. Septifany, A. L. Nugraha, and M. Awaluddin, "Analisis Optimalisasi Rute Pemadam Kebakaran Berdasarkan Area Cakupan Pipa Hidran Di Kota Semarang," J. Geod. Undip, vol. 6, no. 3, pp. 28-36, 2017.

[7] A. L. Setyabudhi, "Perancangan Sistem Informasi Pengolahan Data Absensi dan Pengambilan Surat Cuti Kerja Berbasis Web," JR J. Responsive Tek. Inform., vol. 1, no. 1, pp. 11-22, 2017.

[8] E. Arribe, "Aplikasi smart tourism pada Dinas Pariwisata Kabupaten Kampar guna mempromosikan Destinasi Ekowisata Kabupaten Kampar," Theor. Pract. Tour., vol. 1, no. 2, pp. 132-148, 2018.

[9] S. A. Pratiwi, I. M. Sukarsa, and I. K. A. Purnawan, "Rancang Bangun Aplikasi Sistem Pemesan Bunga Berbasis Android," J. Ilm. Merpati (Menara Penelit. Akad. Teknol. Informasi), vol. 2, no. 2, pp. 205-214, 2016.

[10] W. E. Y. Retnani, D. Istiadi, and A. Roqib, "Pencarian SPBU Terdekat dan Penentuan Jarak Terpendek Menggunakan Algoritma dijkstra (Studi Kasus di Kabupaten Jember)," J. Nas. Tek. Elektro, vol. 4, no. 1, p. 89, 2015. 